\title{
Mercado global de carbono e governança global do clima: desafios e oportunidades
}

\section{Global Carbon Market and Global Climate Governance: Challenges and Opportunities}

\author{
Luana das Graças Queiróz FARIAS* \\ Andrea Cardoso VENTURA** \\ Danielle Soares PAIVA*** \\ Guineverre Alvarez Machado de Melo GOMES ${ }^{* * * *}$ \\ José Célio Silveira ANDRADE*****
}

\begin{abstract}
RESUMO
A mudança climática tem sido um desafio à diplomacia internacional e à Governança Ambiental Global (GAG), demandando um esforço coletivo entre governos, mercado e sociedade civil no sentido de buscar alternativas possíveis à mitigação e/ou adaptação ao fenômeno. Até o momento, a maior parte destas estratégias está focada em instrumentos de mercado, operacionalizados no âmbito do mercado global de carbono. Parte integrante de pesquisa científica interdisciplinar e multi-institucional sobre Governança Global do Clima (GGC) e mercado global de carbono, coordenada pela Universidade Federal da Bahia (UFBA), o presente artigo discute as oportunidades e os desafios do mercado global de carbono como mecanismo de GGC. Para tanto, é realizada ampla revisão bibliográfica e documental sobre o mercado de carbono como instrumento de GGC, visando contribuir para as reflexões e tomadas de decisão para sua maior eficiência no pós-Kyoto. Infere-se, portanto, que os mercados nas vertentes regulado e voluntário não vêm sendo utilizados de forma a alcançar a eficácia que o problema das mudanças climáticas requer, embora tenham ocorrido avanços no número de projetos de redução de Gases Efeito Estufa (GEE), principalmente entre os países em desenvolvimento.
\end{abstract}

Palavras-chave: governança global do clima; mercado global de carbono; mudanças climáticas.

\footnotetext{
* Doutora em Administração (UFBA). Professora da Universidade do Estado da Bahia (UNEB). E-mail: luanafffarias@yahoo.com.br

"* Doutora em Ingeniaría Industrial (Universidad Politécnica de Madrid, Espanha). Pesquisadora integrante do Núcleo de Política e Administração em Ciência e Tecnologia (NACIT) e do Laboratório de Análise Política Mundial (LABMUNDO) da Universidade Federal da Bahia (UFBA).E-mail: andreaventurassa@gmail.com

**** Mestra em Administração (UFBA). Doutoranda em Administração pela Universidade Federal da Bahia (UFBA) e Professora do Curso de Administração do Centro Universitário Jorge Amado (UNIJORGE) e da Pós-Graduação da Universidade Salvador (UNIFACS). E-mail: paivadani@hotmail.com

***** Mestra em Desenvolvimento Regional e Meio Ambiente (UESC). Doutoranda em Administração na Universidade Federal da Bahia (UFBA). E-mail: guineverre2@hotmail.com

****** Doutor em Administração (UFBA). Professor do Departamento de Estudos Organizacionais da Escola de Administração da Universidade Federal da Bahia (UFBA).E-mail: jcelio.andrade@gmail.com.br
} 


\begin{abstract}
Climate change has been a challenge to international diplomacy and to Global Climate Governance (GCG) involving governments, companies and civil society. It is fundamental to understand the role of the global carbon market in GCG, analyzing the opportunities and challenges of this instrument for the post-Kyoto period. This paper discusses the opportunities and challenges of the global carbon market as a mechanism of GCG. This study is part of an interdisciplinary and multi-institutional research project about Global Climate Governance and Carbon Market coordinated by the Federal University of Bahia, Brazil. It is based on a literature review of national and international academic publications, as well as institutional documents from the United Nations International Panel on Climate Changes (IPCC) and UNFCCC.
\end{abstract}

Keywords: global climate governance; global carbon market; climate change.

\section{Introdução}

Desde a realização da Conferência das Nações Unidas sobre o Meio Ambiente e o Desenvolvimento (CNUMAD) - mais conhecida como Rio-92 ou Eco-92, em que foi ratificada a Convenção-Quadro das Nações Unidas sobre Mudanças do Clima (CQNUMC) -, muito vem sendo discutido sobre formas de amenização das mudanças climáticas. Esse tema, frequentemente abordado na visão realista por alguns atores políticos na agenda internacional, considera que os Estados Nacionais são os principais definidores dos regimes ambientais internacionais e, a partir da década de 90, vem ganhando expressividade no âmbito das negociações entre países (MARTINS e FERREIRA, 2011). Ocorre que, decorridos mais de vinte anos da Rio-92, poucos avanços concretos são percebidos no que diz respeito ao clima (WORLD METEOROLOGICAL ORGANIZATION, 2012), apesar das diversas negociações e proposições decorrentes da Governança Ambiental Global (GAG).

Governança pode ser entendida como uma série de acordos entre atores estatais e não estatais fortemente direcionados para abordagens de colaboração para resolução de problemas por meio do fortalecimento e da mobilização dos atores estratégicos (CADMAN, 2012; FARIAS e ANDRADE, 2012). Na perspectiva dos acordos climáticos, os desafios impostos atualmente abrangem os papéis do planejamento e dos incentivos econômicos na "descarbonização" da economia global, das políticas de adaptação, das negociações internacionais, dos mercados de carbono e da decisiva questão da energia. Assim, a mudança climática está no centro da geopolítica mundial e demanda competência de resposta da comunidade internacional (GIDDENS, 2010).

Reconhece-se, ainda, a importância dos mercados na tentativa de mitigação das mudanças climáticas e também do Estado, atuando, em particular, por meio da Governança Global do Clima (GGC) e de seus diversos mecanismos econômicos e políticos, num desafio constante e que exige o envolvimento de uma diversidade de atores internacionais, órgãos e agências, bem como outros países, caso deseje ser eficaz (GIDDENS, 2010). Outras abordagens sobre o tema defendem ainda a necessidade de uma GGC articulada em vários níveis (multi-level), com ações, estratégias, políticas públicas e programas nos níveis internacional, regional, nacional e local (MARTINS e FERREIRA, 2011). Conforme destaca Pohlmann (2011), é necessário reconhecer-se a importância da coerência e necessidade de total articulação entre as decisões tomadas em âmbito internacional, visto que, em última análise, sua operacionalização depende das estratégias a serem implantadas em nível nacional e, posteriormente, no local.

Diante da complexidade da problemática climática, que não respeita limitações geográficas, a GGC vem sendo elaborada em um ambiente de crescente segmentação (que envolve interesses de diversos setores organizacionais e produtivos) e fragmentação (tanto verticalmente, envolvendo atores das esferas supranacional, internacional, nacional e subnacional, quanto horizontalmente, diante do múltiplo envolvimento de atores de distintos sistemas) (BIERMANN e PATTBERG, 2008), ensejando análises detalhadas sobre sua estrutura e formas de 
articulação. Adicionalmente, o enfrentamento do aquecimento global força a emergência de uma perspectiva de política de longo prazo, que demanda planejamento, novos conceitos (dentre eles a ideia do Estado assegurador) e reforça que a resposta efetiva para mudanças climáticas deverá ser multilateral, engajando nações e demais atores sociais a trabalharem em conjunto.

Entre os principais resultados das negociações em busca de uma governança global para o clima encontra-se o Protocolo de Kyoto (PK), tratado internacional multilateral sobre o clima firmado em 1997 e em vigor desde 2005. Originado de diálogos que envolveram mais de 120 países (com delegações representadas por governos, empresas, sociedade civil, cientistas e outros), o PK surgiu como um instrumento de GGC visando ao estabelecimento de metas de redução de Gases do Efeito Estufa (GEE) para mais de cinquenta países - alguns dos maiores emissores à época. A intenção era, para o primeiro período de vigência do documento (20082012), alcançar uma redução, em média, de 5,2\% dos níveis de emissão desses países em comparação aos níveis de 1990.

Visando facilitar o alcance destas metas de redução, o PK adotou a utilização de "mecanismos de flexibilização", que permitem aos governos nacionais contabilizarem suas reduções de emissões por meio de projetos realizados em outros países. Desta forma, o PK constitui-se no marco legal para a criação do Mercado Global de Carbono, ambiente em que se comercializam os chamados "créditos de carbono", ativos financeiros que representam o volume de $\mathrm{CO}_{2}$ reduzido ou removido da atmosfera por um projeto.

O Mercado Global de Carbono atualmente opera nas modalidades regulada e voluntária. A primeira rege-se pelas normas e regras estipuladas no PK e instrumentalizadas pela Organização das Nações Unidas. A segunda não se vincula oficialmente àquele marco legal, mas, de forma mais flexível, estabelece seus critérios de operação e permite maior participação e diversidade de atores (ONGs, empresas privadas, pessoas físicas, etc.), delimitando-se a partir da relação entre estes e da atuação de padrões internacionais definidores das regras de concepção dos projetos (PAIVA, ALVAREZ e ANDRADE, 2012).
Não obstante o encerramento do primeiro período de compromissos do PK, ao final de 2012, existe uma grande incerteza sobre o segundo período de vigência do Protocolo (definido entre 2013-2020 na $18^{\text {a Confe- }}$ rência das Partes, em Doha, Qatar) e, consequentemente, acerca da estruturação da GGC no chamado pós-Kyoto. Esta incerteza está diretamente relacionada às diversas críticas existentes, tanto por parte da comunidade científica (BOYD et al., 2009; GIDDENS, 2010; BUMPUS e COLE, 2010) quanto do movimento ambientalista global (VENTURA e ANDRADE, 2011; CÚPULA DOS POVOS, 2012) sobre a baixa contribuição do Mercado Global de Carbono para o cumprimento do duplo objetivo proposto pela CQNUMC: a redução da emissão de GEE e a promoção de desenvolvimento sustentável nos países hospedeiros.

Diversos estudos, a exemplo CDM Policy Dialogue (2012), vêm discutindo como o mercado global de carbono poderia ser mais eficiente neste duplo objetivo. Outros, mais críticos, afirmam a necessidade de uma forte reformulação nas estratégias e formas de participação e cooperação intergovernamental, especialmente no que diz respeito às economias emergentes (MATTOO e SUBRAMANIAN, 2013) e à necessidade de que estes mecanismos possam, de fato, garantir o desenvolvimento e a transferência de financiamento e tecnologias que propiciem aos países menos desenvolvidos não apenas um desenvolvimento com menos carbono, mas também redução de desigualdades sociais entre as nações e internamente em cada uma delas (ANDRADE et al., 2009). Assim, o mercado de carbono tem sido visto com desconfiança por alguns, que questionam sua probabilidade de êxito e uma possível má utilização política deste instrumento ligado à governança global (GIDDENS, 2010), bem como apontam para uma baixa eficácia e distorções (VIOLA, 2009; GOODMAN, 2012), a exemplo da concentração de projetos em países em estágios mais avançados de desenvolvimento e sua quase inexistência nos países mais pobres (BOZMOSKI, LEMOS e BOYD, 2008).

Desta forma, considera-se de fundamental importância compreender o papel do Mercado Global de Carbono enquanto instrumento da GGC, analisando-se os desafios e as oportunidades para o período pós-Kyoto. Este artigo busca discutir essa temática, situando o 
Mercado Global de Carbono entre os mecanismos de GGC, caracterizando seus atores e regras do jogo, bem como apresentando algumas das visões predominantes em relação às suas limitações em eficácia e desempenho, propondo, ao final, oportunidades de melhoria para as futuras negociações da GGC. O estudo, parte integrante de pesquisa científica interdisciplinar e multi-institucional coordenada pela Universidade Federal da Bahia (UFBA), dentro do projeto Governança Global do Clima e o Mercado Global de Carbono, utilizou como procedimento metodológico as pesquisas bibliográfica e documental, caracterizadas por coleta de dados em material já publicado na literatura nacional e internacional acerca da GGC, das vertentes do mercado global de carbono e documentos institucionais, a exemplo de informes da ONU e do IPCC ligados à temática.

Assim, além da presente introdução, o artigo realiza uma contextualização geral sobre a GGC, caracterizando seus atores, instrumentos e mecanismos (seção 2); apresenta um de seus principais instrumentos, o Protocolo de Kyoto, expondo os mecanismos de mercado dele decorrentes (seção 3); e realiza uma análise sobre suas principais limitações, discutidas pela literatura atual (seção 4). Ao final, apresenta quais seriam algumas oportunidades de melhoria para a configuração dos mecanismos que serão adotados no futuro da GGC.

\section{Compreendendo a governança global do clima (GGC)}

Para Okereke, Bulkeley e Schroeder (2009), quando analisada sob o ponto de vista dos Estados, a governança estaria diretamente relacionada aos paradigmas assumidos sobre a natureza das relações internacionais, incluindo a forma e a função do Estado, a natureza e a locação do poder e autoridade e a concepção de legitimidade na arena internacional. Para além desta concepção, Milani (2008) destaca que a "ecopolítica" internacional já não se desenvolve mais apenas pelos Estados, pois os princípios de uma soberania incondicionada, norteadora da relação sociedade-Estado e da não ingerência nas relações internacionais, estão sendo questionados pela nova ordem mundial e seus novos personagens, em especial pelo princípio da responsabilidade ambiental e seus desafios transnacionais. Ainda nesta abordagem, Mello (1999) aponta a preponderância de atores não governamentais nas relações intra e inter Estados e a crescente autonomia dos mercados financeiros (e suas facilidades para movimentação de capital entre países) como elementos que questionam o papel do Estado e põem em questão a noção clássica de soberania.

A governança, assim, tem sido identificada como um sistema de direção, coordenação ou controle que ocorre em várias escalas espaciais (CADMAN, 2012), ultrapassando as ações de governos, vez que o termo governo sugere a existência de uma autoridade formal, responsável pela implementação de políticas instituídas; já governança refere-se àquelas atividades apoiadas em objetivos comuns, compartilhados por diferentes esferas, desde instituições governamentais até mecanismos informais de cunho não governamental (CAMARGO, 2005). Seria, assim, um padrão de articulação e cooperação entre atores sociais que está representado num plano muito mais amplo do que a dimensão estatal, mas sim na sociedade como um todo (SANTOS, 1997). Com o aprofundamento dos processos de globalização em suas mais distintas dimensões (econômica, social, ambiental, cultural, política...), diversas esferas da vida social e internacional passam a fazer parte de uma agenda de discussões em âmbito global. Afinal, "problemas globais exigem responsabilidades globais" (LOPES, 2009, p. 2). Dentre eles, a questão ambiental emerge com destaque especial, especialmente pelo fato de que muitos dos problemas ambientais ultrapassam fronteiras geográficas e políticas. As questões vinculadas ao meio ambiente passaram das relações entre Estados ao patamar planetário, com a globalização inserindo no contexto macrossocial os níveis microssociais (COMISSÃO SOBRE GOVERNANÇA GLOBAL - CGG, 1996).

Torna-se, então, necessária a construção de um novo cenário, pautado na superação da noção de espaço e fronteiras decorrente da globalização e baseado na intensificação dinâmica entre os principais atores que compõem a arena internacional (CASTELLS, 1999). Seguindo esse raciocínio, estudiosos do tema têm defendido a integração e a complementaridade de atores no cenário da globalização, sobretudo na relação entre Mercado, Estado e Terceiro Setor (PEREIRA, 1999; CGG, 1996; ROSENAU, 2000). Também se tem pensado 
em uma "nova governança" como um novo processo de governar, em que as questões ambientais (e daí Governança Ambiental Global - GAG) articulam fortemente uma tendência para a interação entre redes descentralizadas compostas de múltiplos atores funcionando em múltiplos níveis, concebendo uma arena política onde grupos divergentes (Estado e não Estado) desenvolvem um pluralismo vigoroso (CADMAN, 2012; RHODES, 1997; LAFFERTY e MEADOWCROFT, 1996).

Embora o termo GAG venha sendo aplicado em campos variados, com sentidos diferentes (GONÇALVES, 2005), na literatura recorrente, vários autores ressaltam a necessidade de uma GAG operando em vários níveis (multi-level), com ações, estratégias, políticas públicas e programas nos níveis internacional, regional, nacional e local (GUPTA, 2007). Fixa-se, nessa abordagem, que a definição da governança clássica encontra-se superada, ensejando o surgimento de uma governança em múltiplos níveis, priorizando uma abordagem informal, participativa e integrada que atenda aos interesses das pessoas e das instituições (LEVY e NEWELL, 2005). Assim, a GAG pode ser considerada um agrupamento de princípios, organizações, instrumentos, instituições, agências, mecanismos de financiamento e normas mais ou menos institucionalizadas (CRUZ, 2004) direcionadas e articuladas à consecução de objetivos comuns relacionados ao meio ambiente. As organizações internacionais governamentais, empresas transnacionais, ONGs, cientistas, Governos, empresas e integrantes da sociedade civil desempenham um papel importante no gerenciamento das questões ambientais (ESTY e IVANOVA, 2005), em que os acordos e coalizões viáveis dependem muito mais da capacidade de diálogo e aceitação de pontos de vista diferentes do que do uso da força e seus meios de subjugação (WEISS e PINHEIRO DO NASCIMENTO, 2010). O termo tornou-se chave na política de meio ambiente e recursos naturais, visto que quase todos os processos e estruturas de política ambiental que transcendam as fronteiras nacionais são descritos como parte da GAG.

As questões relativas às mudanças climáticas e à emissão de GEE para a atmosfera terrestre são apenas um dos exemplos - mas provavelmente o de maior complexidade - que expõe a necessidade de uma abordagem diferenciada das estruturas que compõem o quadro da governança ambiental direcionada e impõe uma abordagem mais própria para entendimento de seus mecanismos e recentes manifestações.

\section{Especificidades e instrumentos da GGC}

As mudanças climáticas emergem como um importante tema da diplomacia internacional e, consequentemente, também da GAG, na primeira Conferência das Nações Unidas sobre o Meio Ambiente Humano, realizada em Estocolmo, em 1972 (ANDRADE, 2009). Vinte anos após o início das discussões, na CNUMAD (evento internacional mais conhecido como Eco-92 ou Rio-92), formalizou-se o início de ações globais para o enfrentamento das mudanças climáticas. Neste momento, criou-se a Convenção-Quadro das Nações Unidas sobre Mudança do Clima (CQNUMC ou UNFCCC, na sigla em inglês), cujo objetivo principal era garantir a estabilização da concentração dos GEE na atmosfera - grupo formado pelo Dióxido de Carbono $\left(\mathrm{CO}_{2}\right)$, Metano $\left(\mathrm{CH}_{4}\right)$, Óxido Nitroso $\left(\mathrm{N}_{2} \mathrm{O}\right)$, Perfluorcarbonos (PFCs), Hidrofluorcarbonos (HFCs) e Hexafluoreto de Enxofre $\left(\mathrm{SF}_{6}\right)$-, prevenindo a sua influência no sistema climático mundial.

Institucionaliza-se, naquele momento, a chamada Governança Global do Clima (GGC), também denominada global climate change governance em Barret (2009), governance for/of climate change em Meadowcroft (2009) e Cadman (2012) e climate governance em Okereke e Bulkeley (2007), entre outras. Para Biermann e Pattberg (2008), as principais particularidades que diferenciariam a GGC da governança ambiental tradicional são: (i) a emergência de novos tipos de agências e atores adicionais aos governos nacionais; (ii) a emergência de novos mecanismos e instituições que vão além das tradicionais formas estatais de decisão; e (iii) a crescente segmentação e fragmentação em diferentes níveis e esferas (BIERMANN e PATTBERG, 2008).

Apesar de a UNFCCC demonstrar a existência de um consenso internacional sobre a necessidade de medidas visando à redução da emissão dos GEE, a primeira meta específica para os países somente foi estipulada cinco anos depois da Rio-92, já em 1997, durante a $3^{\text {a }}$ Conferência das Partes (COP-3), realizada em Kyoto, 
no Japão, quando foi proposto o PK. Não obstante a realização de sua $18^{\mathbf{a}}$ edição, em 2012 , em Doha, governantes, organismos internacionais, organizações não governamentais, empresas e cientistas ainda não foram capazes de estabelecer regras mínimas de funcionamento do regime internacional climático.

Considerado o principal instrumento da GGC, o PK estabelece metas específicas para mais de cinquenta países reduzirem suas emissões dos GEEs, em média, 5,2\% em relação aos níveis de emissão de 1990, o que deveria ser alcançado no então período de vigência do Protocolo (2008-2012). Visando facilitar o alcance destas metas, e seguindo experiência bem-sucedida de comercialização de créditos por boas práticas ambientais advinda do Protocolo de Montreal, o PK adota três mecanismos de flexibilização - Implementação Conjunta, Comércio de Emissões e Mecanismos de Desenvolvimento Limpo (MDL) - que, juntos, se instituem como instrumentos econômicos baseados nos princípios da eficiência e também asseguram o cumprimento das estipulações da CQNUMC ou UNFCCC (SEIFFERT, 2009; GOLDEMBERG, 2005), como se verá na seção seguinte.
A complexidade de atores, instrumentos e mecanismos da GGC pode ser sintetizada como apresentado no Quadro 1.

Conforme se infere do quadro acima, a GGC vem apoiando-se nos três instrumentos de regulação e gestão ambiental dominantes na arena político-institucional do meio ambiente nas últimas décadas:

1) Comando e Controle: representando a regulação estatal por meio de imposições legais, possibilitando a manutenção de padrões mínimos de qualidade ambiental. Especialmente a partir da década de 1990, diversos atores e autores, a exemplo de Barde e Pearce (1991) e World Bank (1992), criticam a eficácia deste instrumento para a gestão ambiental. Tendo em vista que as mudanças climáticas representam um problema global cuja solução depende fortemente das estratégias regionais/nacionais/locais de mitigação da emissão de GEE e não sendo possível a estipulação de uma norma global coerciva, deixa-se para as instâncias nacionais e subnacionais a utilização de instrumentos de

QUADRO 1 - COMPOSIÇÃO ATUAL DA GOVERNANÇA GLOBAL DO CLIMA

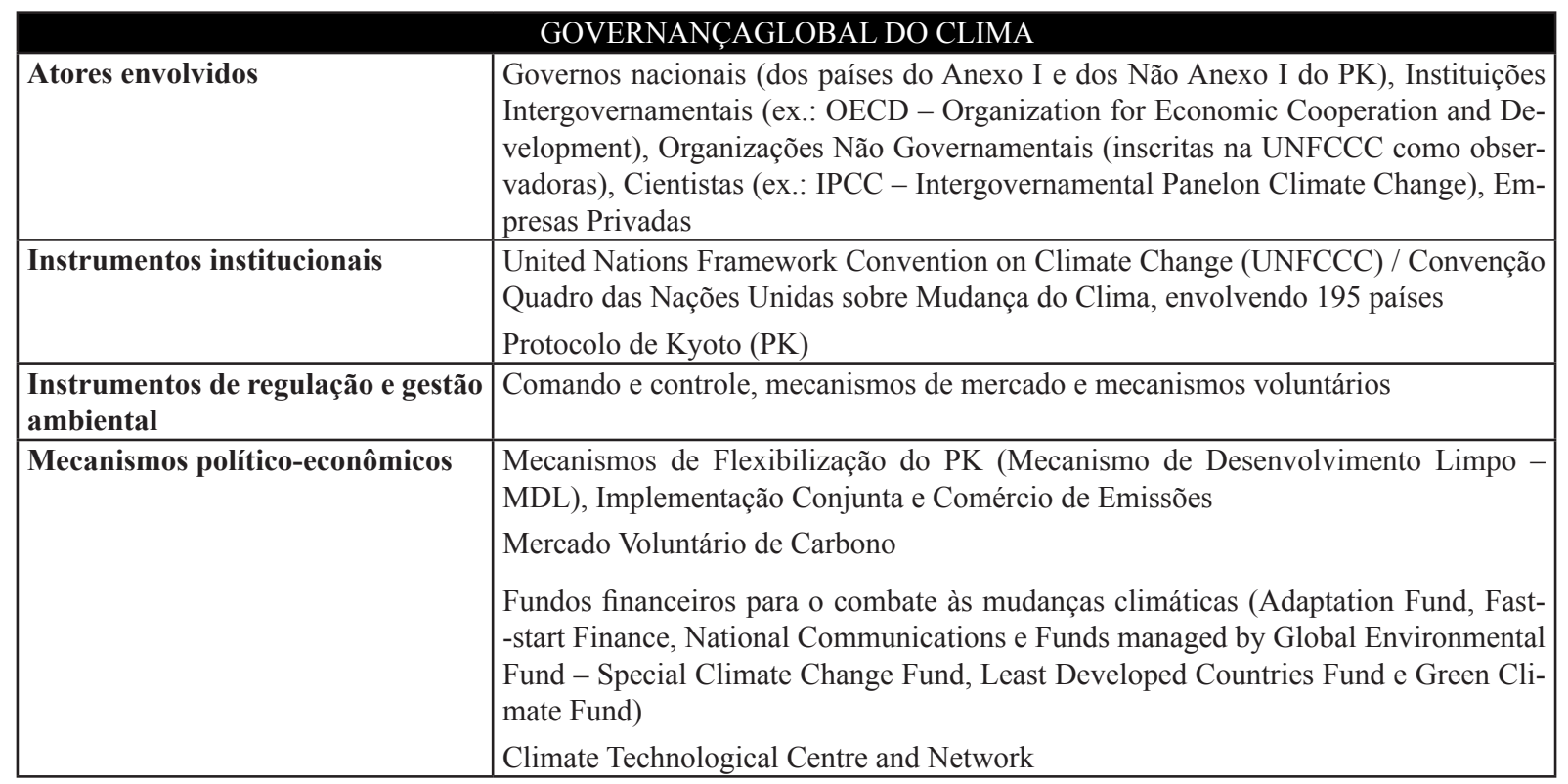

FONTE: Elaboração própria (2012). 
comando e controle. Desta forma, estabeleceu-se um acordo global geral, o PK, cujas metas de redução de GEE específicas para cada país e suas formas de alcance dependem da aprovação posterior de normas nacionais. Visando complementar os instrumentos de comando e controle, recorreu-se a mecanismos econômicos de mercado mais compatíveis com a economia de mercado vigente mundialmente para a regulação dessa questão.

2) Mecanismos de Mercado: expondo os instrumentos econômicos de regulação ambiental, têm sua origem no princípio do poluidor-pagador, em que o agente causador da poluição ou degradação ambiental deve, de alguma forma, internalizar as externalidades ambientais negativas oriundas de suas atividades ou compensar as pessoas afetadas e o meio ambiente, conceito discutido desde a Conferência das Nações Unidas sobre o Meio Ambiente de 1972, em Estocolmo (PUPPIM DE OLIVEIRA, 2003). Especialmente com o aprofundamento da globalização, tem-se o mercado como ator importante na regulação de relações entre indivíduos e organizações e percebe-se que nas discussões climáticas este papel encontra-se altamente fortalecido, especialmente pelo advento do Mercado de Carbono.

3) Mecanismos Voluntários: retratam um ambiente extremamente competitivo em que, cada vez mais, ações que demonstrem a preocupação das empresas com questões sociais e ambientais são valorizadas em função da necessidade de legitimação social dessas empresas. Conforme relembra Puppim de Oliveira (2003), esta autorregulação voluntária, não estipulada por normas formais presentes no comando e controle, é representada, por exemplo, por certificações como a ISO 14001 (de gestão ambiental) e pela Forest Stewardship Council (FSC, relativa a florestas). Especificamente no caso brasileiro, já foram criadas pela Associação Brasileira de Normas Técnicas (ABNT) a ISO 14065, de 2007, que regula a forma de contabilização dos GEE, e a ABNT NBR 15948, de 2011, que traz princípios e recomendações para a negociação de créditos no mercado voluntário de carbono.

Tanto os mecanismos de mercado como os voluntários representam, em análise integrada, instrumentos econômicos complementares aos instrumentos de comando e controle, fornecendo incentivos para que as organizações (e suas respectivas nações) possam avançar para além dos requisitos exigidos pela legislação. Para Puppim de Oliveira (2003), estes instrumentos levariam, ao menos teoricamente, à alocação mais eficiente de recursos econômicos, incentivando o melhoramento tecnológico em prol da qualidade ambiental. Ademais, para Hermann et al. (2012), as alterações no clima não podem ser detidas, a menos que haja uma combinação de diferentes instrumentos, sejam eles de comando e controle ou institucionais.

As condições de GGC local a global - valendo-se principalmente de todos os atores e acordos multilaterais, instrumentos de comando-controle e de ferramentas econômicas - são fundamentais para a redução da fragmentação da arquitetura da governança global, articulando-se com agentes e instituições que tratam a questão dentro ou fora do sistema formal ou das Nações Unidas. Não obstante todos os esforços empreendidos, até o momento há dúvidas sobre como se dará a GGC no segundo período de vigência de Kyoto (2013-2020) e ainda depois disso, em virtude dos desafios que precisam ser enfrentados desde já. Dentre os já citados, destaca-se ainda o que alguns autores identificam como a dependência da GGC em relação ao mercado e seus instrumentos e na pluralidade de agentes e ações que não necessariamente convergem para os mesmos objetivos (CGG, 1996). Nesta perspectiva, é crucial compreender em que aspectos um mecanismo político-econômico, como o mercado de carbono, pode apoiar as ações da GGC.

\section{O Mercado Global de Carbono}

O Mercado Global de Carbono é constituído pelas modalidades regulada e voluntária. O mercado regulado é organizado em um ambiente institucional no qual os participantes estão submetidos à legislação e normas nacionais ou globais, que estabelecem critérios e regras para concepção de projetos e comercialização das Re- 
duções Certificadas de Emissões (RCEs) oriundas dos projetos de MDL. O mercado de carbono voluntário, por sua vez, é caracterizado por um ambiente no qual as regras e normas emergem das relações entre os agentes participantes desse mercado, cujos projetos de mitigação e/ou redução de GEE estão submetidos a Padrões Internacionais (PIs), que fixam regras próprias para sua concepção (SOUZA, PAIVA e ANDRADE,2011).

\section{O Mercado Regulado de Carbono}

Considerando-se que os países industrializados são, comprovadamente, os principais responsáveis pela emissão histórica de GEE na atmosfera e levando-se em conta os argumentos de que os países em desenvolvimento não poderiam, nesse ponto de vista, equiparar-se aos desenvolvidos, sob pena de terem o seu próprio crescimento dificultado, a UNFCCC, ao elaborar o PK, dividiu os países em categorias: a) "Anexo I", formado por 39 países tidos como industrializados, com metas de redução de emissões a serem alcançadas no primeiro período do protocolo (2008-2012), definidas, em média, em 5,2\% em relação ao ano-base de 1990; b) "Não-Anexo I": comporta uma categoria formada pelos países em desenvolvimento, do qual faz parte o Brasil, sem metas de redução obrigatórias definidas (SEIFFERT, 2009; LIMIRO, 2009).

Para o cumprimento destas metas, foram criados mecanismos de flexibilização que permitem a realização de compra e venda de Reduções Certificadas de Emissão (RCE) (SIMONI, 2009) entre países. Como apresentado anteriormente no Quadro 1, são eles: (i) o Comércio de Emissões (CE), que desencadeou um livre comércio de direitos de redução de emissões em nível internacional, o que, segundo Seiffert (2009), permitiu separar quem pagará pelo controle de quem instalará o controle; (ii) a Implementação Conjunta (IC), que permite que países com metas fixadas pelo PK adquiram de outros países desenvolvidos Unidades de Redução de Emissões (URE) ${ }^{1}$ que têm por objetivo a captura e/ou sequestro de GEE e; (iii) o MDL, que é único dos mecanismos do PK que permite a participação de países em desenvolvimento, como o Brasil, que não possuem metas compulsórias de redução de GEE (SEIFFERT, 2009). O MDL constitui-se então em um mecanismo adicional para o cumprimento das metas pelos países desenvolvidos e suas respectivas empresas, a partir da compra de créditos de carbono. Trata-se de uma ferramenta de mercado que visa equilibrar desenvolvimento econômico e meio ambiente por intermédio da comercialização das reduções de GEE decorrentes da implementação desses projetos em determinados países (SIMONI, 2009). Tal estrutura permite a participação de nações em desenvolvimento nesse cenário, ao atuarem como hospedeiras de projetos MDL, ou seja, locais em que projetos que provocam redução de GEE ou sequestro de dióxido de carbono $\left(\mathrm{CO}_{2}\right)$ se estabelecem e recebem financiamento/investimento de países desenvolvidos, por meio da aquisição de certificados que comprovem esta redução.

O estabelecimento destes mecanismos de flexibilização é considerado um dos pontos de maior impacto trazidos pelo PK para as negociações internacionais. Isso porque se introduz a possibilidade da comercialização das reduções de emissão efetivamente realizadas, permitindo que um país alcance suas metas individuais por meio de projetos implementados em outros países. Logo, o mercado de carbono pode ser definido como a "compra e venda de licenças para emissões (direito de poluir) ou reduções de emissões (offsets) que foram respectivamente ou distribuídos por um órgão regulatório ou gerados por projetos de redução de emissões de GHGs [gases de efeito estufa, na sigla em inglês]" (ECOSYSTEM MARKETPLACE, 2011, p. 5).

Dentre os participantes do mercado regulado estão os consultores, auditores, brokers, desenvolvedores dos projetos, especuladores, serviços de corretores, dentre outros que visam dar liquidez à comercialização de créditos de carbono, cujos interesses são distintos. As negociações (de compra e venda) dos créditos de carbono, que são ativos de valor econômico, são realizadas em mercado de balcão, por meio de acordos varejistas, entre as partes interessadas. Para que um contrato seja celebrado, faz-se necessário que a empresa detentora das

\footnotetext{
${ }^{1}$ Igual a 1 tonelada (métrica) de $\mathrm{CO}_{2}$ não emitido (reduzido ou sequestrado), por meio de projeto de implementação conjunta, entre países do Anexo $B$.
} 
RCEs dos projetos de redução de GEE transfira-as ou, contratualmente, obrigue-se a transferi-las, na condição de vendedora, e, portanto, o comprador (empresas e/ou governos signatários do PK) pague os valores correspondentes às negociações em acordos pactuados entre as partes (LORENZONI NETO, 2009).

As compras das RCEs, de acordo com Conejero (2007), são realizadas com dinâmicas semelhantes às compras efetuadas no mercado de commodities, na maioria das transações, além das operações de investimentos, oriundos de empresas de países desenvolvidos em projetos dessa natureza, com foco na obtenção dos créditos de carbono para compensação dos excedentes de emissões.

Uma das características mais peculiares do mercado regulado é a possibilidade de, na ausência da possibilidade de uma ferramenta de comando e controle global, estipularem-se metas obrigatórias aos países integrantes do Anexo I no próprio PK, mas que foram reguladas e fiscalizadas em nível nacional. Assim, o tratado possibilitou a estipulação consensuada das obrigações a serem cumpridas por cada país, cabendo a este, internamente, estabelecer estratégias de comando e controle para garantir que as empresas adequassem suas ações a fim de garantir reduções, ou de efetuarem negociações, no âmbito dos mecanismos de flexibilização, para comprovar que esta redução deu-se em outro país.

\section{O Mercado Voluntário de Carbono}

O mercado alternativo ao mercado regulado pelo $\mathrm{PK}$, o chamado mercado voluntário de carbono (MV), constitui-se em ambientes nos quais as negociações de créditos de carbono, intitulados Verified Emission Reduction (VER), se dão por meio de diversos agentes, como os governos, empresas, ONGs, indivíduos, etc. (SIMONI, 2009), que não se encontram sob as regras do PK, fazendo com que os interesses na participação desse mercado sejam diversificados. Para Bayon, Hawn e Hamilton (2009), o MV de carbono possui uma lógica considerada inovadora e de menor custo quando comparado com o mercado regulado. Gillenwater (2007) acrescenta que a aquisição de créditos decorrente do $\mathrm{MV}$ é economicamente racional nos casos em que reduzir as emissões atribuíveis à sua própria atividade é mais dispendioso. Pagar alguém para poluir menos pode ser mais sábio, tanto para o comprador como para a sociedade como um todo, do que reduzir sua própria poluição, porque um montante maior de emissões poderá ser reduzido para determinado dispêndio de recursos.

No MV de carbono, não vinculado às metas obrigatórias estabelecidas pelo $\mathrm{PK}$, a preocupação dos investidores e compradores pauta-se no gerenciamento de seus impactos em relação às mudanças do clima, sua imagem, reputação, interesses em inovações tecnológicas para redução de GEE, legitimidade, necessidade de se prepararem para regulações futuras e/ou planos de revenda de créditos de carbono lucrando com as comercializações (IBRI, 2009). Assim, a atratividade nesses mercados está diretamente associada ao fator credibilidade que as empresas adquirem frente a seus stakeholders. As empresas buscam um bom posicionamento nos mercados em que atuam, a partir de ações de responsabilidade socioambiental, bem como aumento da vantagem competitiva frente aos seus concorrentes.

De acordo com o Instituto Carbono Brasil (2010, p. 1), nesse mercado “os esquemas são financiados por organizações e indivíduos que querem neutralizar o impacto das emissões produzidas pelas suas atividades". Assim, dentre os projetos desenvolvidos no MV de carbono, estão: projetos com metodologias de pequena escala, não viáveis, do ponto de vista econômico, no mercado regulado; projetos que não atendem a critérios estabelecidos pelo MDL; projetos que já computaram créditos retroativos, ou seja, créditos computados antes mesmo do registro do projeto na ONU (SIMONI, 2009). Se por um lado o mercado regulado tem suas regras e metas de reduções fixadas pelo PK, por outro, o MV constitui-se em um ambiente no qual as regras e normas emergem das relações entre os agentes participantes, os chamados Padrões Internacionais (PIs).

Desta forma, os desenvolvedores de projetos ou varejistas que atuam no MV podem se utilizar de regras mais flexíveis, quando comparadas com as estabelecidas pelo mercado regulado pelo PK, já que a forma de organização do MV de carbono é resultado de ações dos próprios agentes comercializadores e vendedores de créditos de carbono (BUMPUS e LIVERMAN, 2008). Isso porque, a partir das interações dos participantes, 
emergem regras que norteiam a comercialização entre esses, bem como permitem que as formas de negociação sejam padronizadas com base em acordos emergidos das transações (os PIs) e não especificamente de um tratado e/ou lei.

Assim, os agentes envolvidos nas transações estabelecem entre si os acordos que vão regulamentar as negociações. Além disso, os meios utilizados para comercializar os créditos de carbono nesse mercado podem estabelecer as suas próprias regras, comuns às partes envolvidas (vendedor e comprador), como, por exemplo, o ambiente de negociação americano, a Bolsa de Chicago, dentre outros ambientes. A fixação do valor justo na transação emerge do mercado e dos agentes nele atuantes.

É importante salientar que, embora as empresas utilizem o MV como um meio para obtenção de créditos de carbono e/ou testarem seu projeto, que em algumas vezes também foi submetido ao mercado regulado, aguardando validação e/ou aprovação, as mesmas não podem utilizar os mesmos créditos para fins de compensação duas vezes. Isso porque a "reciclagem" de créditos de carbono, ou seja, a dupla contabilização, foi motivo de caos no mercado europeu em 2010, quando foi transacionado duas vezes o equivalente a dois milhões de toneladas de $\mathrm{CO}_{2}$ eq pelo governo húngaro para uma organização inglesa.

Tais falhas acarretam em desconfiança por parte dos principais atores do mercado e impactam diretamente a credibilidade das VER negociadas (PASISHNYK, 2010). Elas estão associadas às características de mensuração, fiscalização, contabilização das reduções de emissões, dentre outras, essenciais ao mercado de offset. No entanto, com o estabelecimento dos PIs, a partir da mobilização dos agentes participantes desse mercado, regras foram instituídas de forma a dar ao mercado a credibilidade necessária para seu efetivo funcionamento.

A cada PI cabe determinar o seu conjunto de critérios, os quais servem de guidelines para os proponentes elaborarem seus projetos, visando garantir transparência e credibilidade, aspectos tão necessários para um mercado sem uma instituição de regulação central como o mercado regulado. Assim, para que um projeto seja aprovado e registrado no MV de carbono, é preciso passar pelas etapas do ciclo de validação do projeto, normalmente menos burocrático e oneroso do que no mercado regulado pelo PK. Diferentemente do mercado regulado de carbono, as regras para concepção dos projetos de redução de emissão e ou mitigação de GEE no MV não são únicas. Verifica-se que cada PI estabelece conjuntos de regras distintas. Dentre as regras estabelecidas pelos PIs estão: elaboração do projeto seguindo um documento modelo de concepção; toda redução das emissões de GEE deve ser comprovada/mensurável/ quantificável; as reduções devem ser permanentes, ou seja, o projeto deve reduzir continuamente as emissões de GEE que até então eram emitidas para atmosfera; os projetos devem atender ao princípio da adicionalidade.

\section{Desafios/oportunidades do Mercado Global de Carbono enquanto instrumento de Governança Global do Clima}

Desde o surgimento do Mercado de Carbono, as relações comerciais internacionais vêm se intensificado entre os agentes vendedores, detentores dos créditos, e os compradores interessados na compra desses créditos para o alcance de suas metas ou interesses (SILVA JÚNIOR e ANDRADE, 2011). Isso ocorre uma vez que várias oportunidades de negócios, que têm como premissa equilibrar desenvolvimento econômico e meio ambiente de forma a instituir a sustentabilidade, surgiram gerando perspectivas rentáveis para as empresas, os indivíduos e o meio ambiente, além de contribuir para a redução dos riscos corporativos associados à mudança do clima (LABAT e WHITE, 2007).

Além disto, mais especificamente no que diz respeito ao mercado regulado, há de se considerar a possibilidade de investimentos oriundos dos países desenvolvidos nos países em desenvolvimento, resultando em benefícios econômicos e tecnológicos, corroborando um dos papéis do MDL na promoção da transferência de tecnologia e promoção do desenvolvimento sustentável. Dessa forma, há autores que acreditam que o PK trouxe grandes inovações no combate aos problemas climáticos, por meio das vias de mercado, como mecanismo adequado às falhas existentes no mercado tradicional (LOMBARDI, 2008). Nesta visão, o mercado de carbono, nas duas vertentes, objetiva primeiramente a redução de GEE 
e, por conseguinte, a promoção do desenvolvimento sustentável e a transferência de tecnologia, acarretando em melhorias nos aspectos econômicos, ambientais e sociais para o país hospedeiro dos projetos.

Contudo, o PK tem recebido críticas constantes. Primeiramente, a não participação dos Estados Unidos da América (EUA), o principal poluidor à época, que se recusou a assinar o acordo sob o argumento de prejuízos às suas indústrias e ao desenvolvimento de sua economia. Em segundo, por não ter fixado metas de redução de emissão para os países em desenvolvimento, a exemplo da China, a segunda maior economia do mundo atualmente (VEIGA, 2010). Para Barrett (2009), a ausência de participação dos EUA é a principal falha do PK. Na opinião deste autor, "as medidas tomadas até agora para solucionar as mudanças climáticas falharam" (BARRETT, 2009, p.1). Isto decorre do fato de que não há como garantir que as metas assumidas pelos países sejam efetivamente cumpridas. Apesar de ser um instrumento regulador, o PK não prevê sanções caso alguma das partes deixe de cumpri-lo ou dele se desligue. $\mathrm{Ou}$ seja, ele não representa um instrumento efetivo de comando e controle. Na COP 17, em Durban, a Rússia, o Japão e o Canadá decidiram não fazer parte do segundo período de compromisso do $\mathrm{PK}$, não havendo aplicação de nenhuma penalidade, demonstrando certa fragilidade nesse instrumento enquanto mecanismo de GGC.

Especificamente no que diz respeito às negociações de carbono originadas por Kyoto, o autor afirma que mecanismos como o MDL criaram um "incentivo perverso". É economicamente mais interessante para os produtores adquirirem CERs do que reduzirem efetivamente suas emissões, fazendo com que um grande volume de emissões continue a ser originado nos países do Anexo I sem que, necessariamente, sejam realizados projetos que promovam o esperado desenvolvimento sustentável dos países hospedeiros. Esta opinião é endossada por Bozmoski, Lemos e Boyd (2008), afirmando que é mais barato aos países cumprirem seus compromissos por meio de reduções realizadas em países em desenvolvimento. Os autores afirmam que, devido a este benefício financeiro, os projetos deveriam efetivamente promover mais do que "apenas" tecnologias ambientalmente mais limpas, mas sim auxiliar na promoção de um novo tipo de desenvolvimento em diversos níveis, iniciando-se nos locais onde são desenvolvidos, até chegar à escala global.

Constata-se que, em realidade, o MDLé o mecanismo mais criticado na GGC no que se refere à sua pouca contribuição em relação à promoção de desenvolvimento sustentável em países em desenvolvimento, descumprindo um dos seus objetivos (juntamente com a redução de emissões propriamente dita), conforme apontam diversos autores (SUTTER e PARREÑO, 2007; BOZMOSKI, LEMOS e BOYD, 2008; BOYD et al., 2009). Uma das principais razões para esta falha é que cabe à Autoridade Nacional Designada (AND) de cada país definir os critérios para que um MDL seja considerado como promotor de desenvolvimento sustentável. Não há uma estratégia de comando e controle global, cabendo ao nível nacional regular a questão. Além disso, após aprovados pelas AND, não há uma verificação ou monitoramento específico sobre as questões de sustentabilidade dos projetos. Assim, os objetivos de desenvolvimento do MDL devem ser melhor definidos para ir ao encontro da agenda global de sustentabilidade social e ambiental.

Importante citar, ainda, a disparidade regional existente em projetos do mercado de carbono. Por razões como falta de capacidade institucional e de foco nos investimentos ligados ao clima, países com grandes problemas sociais e ambientais não recebem os investimentos que estão circulando nesta modalidade financeira (BOZMOSKI, LEMOS e BOYD, 2008). De acordo com dados da UNEP (2012), 81\% dos projetos de MDL estão localizados na Ásia e no Pacífico, 13,9\% na América Latina e somente $3,1 \%$ nos países da África.

Outra falha importante apontada pelos estudiosos é o fato de que os projetos de MDL apresentam "falhas de desigualdade de distribuição dos projetos e escolha subótima destes projetos" (BOZMOSKI, LEMOS e BOYD, 2008, p. 22). Para eles, esta falha de distribuição é um indicativo de problemas de governança, que representariam justamente os processos pelos quais as decisões transnacionais que afetam os MDL e o desenvolvimento são realizadas, implementadas e coordenadas.

Ademais, a incerteza quanto ao futuro do PK trouxe consequências desastrosas para esse mecanismo. Os preços dos créditos de carbono têm despencado em meio a um cenário mundial de crise econômica (como 
a verificada na Europa, maior comprador de créditos), corroborando um efeito negativo na utilização desse mecanismo pelo setor privado. Segundo Streck e Lin (2008), o mercado regulado sozinho tinha a promessa de gerar, em 2007, 12 bilhões de euros; entretanto, em 2011, os resultados apontam para um montante de 175 milhões de dólares, com acréscimo de $10 \%$ em relação ao ano anterior (ECOSYSTEM MARKETPLACE, 2012). O crescimento desse mercado, assim como do Mercado Voluntário, tem sido fortemente abalado pela perspectiva econômica desse mecanismo. O preço ainda é o principal atrativo para o setor privado na utilização desse mecanismo, demonstrando a insuficiência de mecanismos exclusivamente financeiros para a promoção de novas estratégias de desenvolvimento que utilizem menos carbono e que sejam sustentáveis.

Ademais, Heimdal et al. (2012) afirmam que, a reboque da baixa de preços, os investimentos tendem a reduzir. Os estudos desses autores apontam para uma diminuição ou parada completa dos investimentos em projetos de MDL, face ao comportamento dos preços e da fraca perspectiva de demanda de crédito até 2020. Desta forma, o ambiente instável existente ao redor do PK e seus mecanismos de flexibilização corroboram a preocupação global existente sobre a crise climática, que impacta em diversos setores da sociedade e, principalmente, da economia, o que tem exigido das instituições públicas e privadas uma nova concepção de produção, a qual busca o equilíbrio entre a estratégia do negócio e o meio ambiente, além de contemplar um processo de produção responsável, com minimização dos impactos, inovações tecnológicas, produção mais limpa e uso consciente dos recursos naturais (KIPERSTOK et al., 2002). Para Simoni (2009), a criação desses Mercados de Carbono (regulado e voluntário) traz consigo uma inovação às práticas de equilíbrio das desproporcionalidades existentes entre desenvolvimento econômico e meio ambiente, onde este último, essencial à existência humana, tem perdido cada vez mais espaço para as práticas produtivas sem um planejamento devido. Na opinião do autor, esses mercados, portanto, se constituem em uma ferramenta de suma importância no auxílio às estratégias das lideranças globais para transição para uma economia de baixo carbono. Contrariamente, para Barrett (2009), o PK e seus mecanismos criaram mecanismos muito modestos de inovação, quando, em realidade, enfrentar as mudanças climáticas exige uma real revolução tecnológica. A principal razão para as poucas inovações seria o fato de que o Mercado de Carbono trabalha com metas de curto prazo. Pesquisa e desenvolvimento requerem investimentos de longo prazo.

Outrossim, tais instrumentos de mercado carregam em si uma limitação crucial, que é a fragmentação. Segundo Michaelowa (2012), a fragmentação pode levar a acordos mais rápidos entre os agentes, resultando na diluição dos compromissos. Além disso, podem permitir que as transações deixem de envolver atores não estatais, fazendo com que as soluções sejam adaptadas às circunstâncias específicas. Logo, o instrumento traz consigo um viés contraditório, pois, dado que a mitigação dos GEEs seja um bem público global, é economicamente ideal que houvesse um acordo global sobre metas de emissões para aproveitar as opções mais baratas de mitigação por intermédio de mecanismos de mercado. No entanto, o que os atores apontam é que há um predomínio do interesse específico de cada ator nesse mercado que nem sempre leva ao objetivo comum global.

Não obstante a crise nos preços praticados no Mercado Regulado e os questionamentos sobre sua efetividade para a promoção de tecnologias mais eficientes e para o desenvolvimento sustentável, há quem sustente a possibilidade de um futuro importante do Mercado de Carbono global nas estratégias para um desenvolvimento com menos carbono. Mota e Tega (2013), por exemplo, apostam no papel a ser desempenhado por micro e pequenas empresas, por meio de estratégias de transferência tecnológica e inovação que levem em conta o fator sustentabilidade. Para as autoras, este tipo de projeto vem obtendo cada vez mais atenção por parte de investidores, que acreditam, especialmente, em projetos desenvolvidos no âmbito do Mercado Voluntário, visto apresentarem maiores exigências de benefícios concretos às localidades onde são desenvolvidos.

Paralelamente, o CDM Policy Dialogue (2012), reconhecendo as limitações atuais do Mercado Regulado, vê no Mercado de Carbono uma oportunidade para que as nações atinjam suas metas de mitigação de maneira flexível e com custos-benefícios eficientes. Para a organização, é necessário que os novos instrumentos econômicos que estão sendo negociados no âmbito do 
pós-Kyoto (acordo que passará a vigorar a partir de 2020, quando encerrado o "segundo período" do PK, acordado na última COP para os anos de 2013-2020) tenham como base, ao menos, quatro requisitos: (i) o aumento da ambição de mitigação, por parte das nações, com a adoção de metas que incorporem a criticidade da problemática ambiental; (ii) a adaptação do MDL às novas condições políticas e de mercado frente à crise global; (iii) reforma nos procedimentos, para que os projetos efetivamente garantam a redução de emissões e a promoção de desenvolvimento sustentável; e (iv) novas estruturas de governança que garantam maior transparência e eficiência organizacional.

Assim, o mercado global de carbono, como um dos principais mecanismos da GGC, pode estar apresentando uma resposta além da perspectiva puramente econômica. E, por outro lado, fica evidente que para aumentar a eficiência desse mercado é preciso que existam incentivos suficientemente fortes para que os participantes tenham algum tipo de benefício, de modo a continuar empreendendo essas iniciativas.

\section{Considerações finais}

Neste artigo buscou-se caracterizar o mercado global de carbono enquanto principal instrumento político-econômico da GGC. A partir dessa análise, foi possível reconhecer que as mudanças climáticas exigem uma resposta global, baseada numa compreensão partilhada dos objetivos a atingir a curto, médio e longo prazos entre todos os atores da GGC, identificando-se múltiplos desafios para utilização quase que exclusiva de mecanismos de mercado para esta consecução.

Sob essa perspectiva, é possível fazer algumas inferências às oportunidades de melhoria para o futuro da GGC, visando à sua efetividade no período pós-Kyoto:

a) Necessidade de novas configurações na GGC, para alinhar os incentivos financeiros ligados ao Mercado de Carbono às prioridades de desenvolvimento mundiais. Uma maneira de se realizar isso seria compensar o excesso de risco existente em tipos específicos de projetos ou na realidade de alguns países, ajustando-se o preço das certidões de carbono negociadas. Como exemplo, os autores sugerem a estipulação de um valor diferenciado (mais elevado) aos projetos de energia renovável e também de projetos desenvolvidos nos países tidos como menos desenvolvidos (Least Development Countries, conforme denominação das Nações Unidas) (BOZMOSKI, LEMOS e BOYD, 2008);

b) A estipulação, por parte da UNFCCC, de cotas mínimas de CERs a serem adquiridas para projetos e países prioritários, a exemplo da África Subsaariana. Os autores sugerem, ainda, que alguns projetos hoje negociados no MVde carbono, a exemplo daqueles mantidos nas regras do PI Gold Standard, sejam incorporados às políticas do Mercado Regulado. Desta forma, exigências mínimas de contribuições ao desenvolvimento sustentável passariam a fazer parte do escopo dos projetos de MDL e do Mercado de Carbono voluntário (BOZMOSKI, LEMOS e BOYD, 2008);

c) Possibilidade de avanços no Mercado de Carbono, a partir das diretrizes apresentadas pelo Nairobi Framework (NF), a fim de promover condições efetivas de desenvolvimento a países menos desenvolvidos. O NF é uma iniciativa das UNDP (United Nations Development Programme), da UNEP (United Nations Environment Programme), do Banco Mundial, do African Development Bank e da secretaria da UNFCCC, visando auxiliar estes países a uma participação efetiva no mercado de carbono global, especialmente por meio da construção de capacidades (UNFCCC, 2012). Desta forma, espera-se que os recursos financeiros e transferência de tecnologia passíveis de serem adquiridos via Mercado de Carbono possam auxiliar não apenas na obtenção de um desenvolvimento com menos carbono, mas também permitir a criação de estratégias eficientes de adaptação.

d) Adoção de estratégias de GGC que possam ser efetivadas em todos os níveis de atuação governamental, desdobrando-se desde as decisões consensuadas em âmbito internacional até chegar às ações efetivas em nível local. É necessário que todas as nações do mundo, independentemente de seu grau de desenvolvimento, incorporem estratégias de mitigação em seus respectivos planos e ações de desenvolvimento.

Obviamente, estas ações não podem estar restritas a instrumentos de mercado, visto as limitações e interesses já apresentados. Desta forma, a GGC futura deverá oportunizar para o desenvolvimento e realização de estratégias de gestão ambiental que incluam instrumentos 
mercadológicos (o que pode ocorrer dentro do próprio mercado de carbono global, desde que realizadas as melhorias necessárias para garantir a redução de emissões de maneira mais ambiciosa e adequada à criticidade do problema, a promoção de desenvolvimento sustentável com atenção ao crescimento com menos carbono e adoção de estratégias de adaptação associadas, além da incorporação de países em desenvolvimento ou menos desenvolvidos aos mercados), associados a estratégias voluntárias por parte de governos e empresas, juntamente com a sociedade civil local e global, bem como a instrumentos de comando e controle, em âmbito nacional, a fim de permitir que as decisões realizadas possam ser fiscalizadas e sua implementação concretizada, mesmo que por meio de sanções e proibições.

O aprofundamento destes conhecimentos poderá permitir a criação de novas estratégias mundiais, com aplicação em todos os níveis governamentais e setoriais, para o período pós-Kyoto, que permitam o desenvolvimento mundial frente ao cenário aparentemente inevitável das mudanças climáticas globais.

\section{Referências}

ANDRADE, J. C. S. O papel das empresas brasileiras participantes do Carbon Disclosure Project na governança ambiental global do clima. Bolsa de Produtividade em Pesquisa CNPq. UFBA, 2009.

; SILVA JUNIOR, A. C.; NAPRAVNIK FILHO, L.; TELESFORO, A. C.; VENTURA, A. C. Clean Development Mechanism (CDM) projects and generation of clean technologies in Brazil In: INTERNATIONAL WORKSHOP ADVANCES IN CLEANER PRODUCTION, 2., 2009, São Paulo. Proceedings.

ASSOCIAÇÃO BRASILEIRA DE NORMAS TÉCNICAS ABNT. ABNT NBR l15948:2011. Mercado de carbono voluntário: Princípios, requisitos e orientações para comercialização de reduções verificadas de emissões. 2011. Disponível em: $<$ http://www.abnt.org.br>. Acesso em: mar. 2011.

BARDE, J. P.; PEARCE, D. W. Valuing the environment: six case studies. London: Earthscan Publications, 1991.

BARRETT, S. Rethinking Global Climate Change Governance. Economics: The Open-Access, Open-Assessment E-Journal, v. 3, n. 5, march 2009.
Diante disso, pôde-se inferir que o mecanismo tradicional e formal (Mercado Regulado de Carbono) não vem sendo utilizado de forma a alcançar a eficácia que o problema das mudanças climáticas requer, embora tenham ocorrido avanços nos projetos de MDL, principalmente entre os países em desenvolvimento. E os Mercados Voluntários de carbono continuam empenhados para que seus instrumentos atendam às expectativas de desempenho dos seus participantes e, ao mesmo tempo, contribuam com a redução de GEE. Os dois mercados são alternativas apresentadas para compatibilizar crescimento econômico com conservação ambiental e, mesmo com dificuldades inerentes a cada vertente, já são passíveis de impactar na GGC e tomar decisões assertivas do ponto de vista da qualidade ambiental e do futuro da vida no planeta.

Todavia, compete a eles, então, o grande papel de promover o desenvolvimento sustentável como caminho para obter equidade social, econômica e ambiental, bem como fomentar políticas internacionais de GGC.

BAYON, R; HAWN, A; HAMILTON, K. Voluntary carbon markets: an international business guide to what they are and how they work. 2. ed. London: Earthscan, 2009.

BIERMANN, F., PATTBERG, P. Global environmental governance: taking stock, moving forward. Annual Review of Environment and Resources, v. 33, p. 277-294, 2008.

BOYD, E.; HULTMAN, N.; ROBERTS, J. T.; CORBERA, E.; COLE, J.; BOZMOKSKI, A.; EBELING, J.; TIPPMAN, R.; MANNA, P.; BROWN, K.; LIVERMAN, D. M. Reforming the CDM for sustainable development: lessons learned and policy futures. Environmental Science \& Policy, v. 12, p. 820-831, 2009.

BOZMOSKI, A.; LEMOS, M. C.; BOYD, E. Prosperous negligence: governing the clean development mechanism for markets and development. Environment: Science and Policy for Sustainable Development, v. 50, n. 3, p. 18-30, 2008.

BUMPUS, A. G.; LIVERMAN, D. M. Accumulation by decarbonization and the governance of carbon offsets. Economic Geography, v. 84, n. 2, p.127-155, 2008. 
; COLE, J. How can the current CDM deliver sustainable development? Wiley Interdisciplinary Reviews: Climate Change, v. 1, p. 541-547, 2010.

CADMAN, T. Evaluating the quality of global governance: a theoretical and analytical approach. Earth System Governance Working Paper, n. 20, 2012.

CAMARGO, A. Governança. In: TRIGUEIRO, A. (Coord.) Meio ambiente no século XXI. 4. ed. Campinas/SP: Armazém do Ipê Autores Associados, 2005.

CASTELlS, M. O poder da identidade. São Paulo: Paz e Terra, 1999.

CDM POLICY DIALOGUE.Climate change, carbon markets and the CDM: a call to action. Executive summary: recommendations of the high level panel on the CDM Policy Dialogue. 2012. Disponível em: <http://www.cdmpolicydialogue.org/>. Acesso em: dez. 2012.

COMISSÃO SOBRE GOVERNANÇA GLOBAL - CGG. NosSa comunidade global: o relatório da Comissão sobre Governança Global. Rio de Janeiro: Editora FGV, 1996.

CONEJERO, M. A. O crédito de carbono do Protocolo de Kyoto como commodity ambiental. In: SOUZA, R. P. de. Aquecimento global e créditos de carbono: aspectos jurídicos e técnicos. São Paulo: Quartier Latin, 2007.

CRUZ, S. C. V. Globalização, democracia e ordem internacional: ensaios de teoria e história. Campinas: Editora da Unicamp: São Paulo, 2004.

CÚPULA DOS POVOS. Declaração Final Cúpula dos Povos por justiça social e ambiental em defesa dos bens comuns, contra a mercantilização da vida. 2012. Disponível em: <http:// www.secretariageral.gov.br/internacional/consultapos2015/ declaracao-cupula>. Acesso em: ago. 2012.

ECOSYSTEM MARKETPLACE. Program assistant, climate action reserve (CAR). 2011. Disponível em: $<\mathrm{http}: / /$ www.ecosystemmarketplace.com/pages/dynamic/web.page. php?page_id $=8083 \&$ section $=$ about_us\&eod $=1>$. Acesso em: mar. 2011.

Back to the future: the state of the voluntary carbon markets. 2012. Disponível em: <http://www.ecosystemmarketplace.com/pages/dynamic/resources.library.page. php?page_id $=8351 \&$ section $=$ our_publications\&eod $=1>$. Acesso em: jun. 2012.

ESTY, D. C.; IVANOVA, M. H. Revitalização da governança ambiental global: um enfoque baseado em funções. In:

(Org.). Governança ambiental global. São Paulo: Ed. SENAC, 2005.
FARIAS, L. G. Q.; ANDRADRE. J. S. Estratégias ambientais do Carbon Disclosure Project e seus reflexos sobre a governança ambiental do clima. In: CONGRESSO NACIONAL DE EXCELÊNCIA EM GESTÃO - CNEG, 8., jun. 2012. Rio de Janeiro. Anais.

GIDDENS, A.The politics of climate change. Cambridge: Polity Press, 2010.

GILLENWATER, M. Redefining RECs (Part 1): Untangling attributes and offsets, [Discussion paper]. Science Technology and Environmental Policy Program. Princeton, NJ: Princeton University, 2007.

GOLDEMBERG, J. O. Caminho até Johanesburgo. In: TRIGUEIRO, A. (Coord.). Meio ambiente no século 21: 21 especialistas falam da questão ambiental nas suas áreas de conhecimento. Rio de Janeiro: Sextante, 2005.

GONÇALVES, A. F. O conceito de governança. In: CONGRESSO NACIONAL CONPEDI, 2005. Fortaleza. Anais.

GOODMAN, J. Climate change and global development: towards a post-Kyoto paradigm? The Economic and Labour Relations Review, v. 23, n. 1, fev. 2012.

GUPTA, J. The multi-level governance challenge of climate change. Environmental Sciences, v. 4, n. 3, p. 131-137, 2007.

HEIMDAL, C. et al. Carbon 2012: a market waiting for godot. Point Cabon. 2012. Disponível em: $<$ http://www.pointcarbon. com/polopoly_fs/1.1814671!Carbon\%202012_FINAL.pdf\$. Acesso em: jun. 2012.

HERMANN, R. R.; KUMAR SWAMI, N.; NGAN, B. V.; QUEIROZ, P. O papel dos programas ambientais voluntários nas políticas de redução dos gases de efeito estufa nos países em desenvolvimento: perspectivas do Brasil, Índia e Vietnã. Bahia Análise \& Dados, v. 21, n. 4, Salvador, Bahia, 2012.

INSTITUTO BRASILEIRO DE RELAÇÕES COM INVESTIDORES - IBRI. O mercado de carbono. Cadernos IBRI. Série Sustentabilidade. 1. ed. 2009.

INSTITUTO CARBONO BRASIL. Mercado de Carbono: Cap-and-Trade. 2010. Disponível em: $<$ http://www.institutocarbonobrasil.org.br/mercado_de_carbono/cap_and_trade $>$. Acesso em: abr.2011.

KIPERSTOK, A. et al. Prevenção da poluição. Programa SENAI Educação a Distância. Tecnologias e Gestão Ambiental - TGA. Brasília: SENAI/DN, 2002.

LABATT, S.; WHITE, R. Carbon finance: the financial implications of climate change. EUA: Jonh Wiley \& Sons, Inc., 2007. 
LAFFERTY, W. M.; MEADOWCROFT, J. Democracy and the environment: prospects for greater congruence. In:

(Eds.). Democracy and the environment: problems and prospects. Cheltenham and Lyme: Edward Elgar, 1996.

LEVY, D. L.; NEWELL, P. J. The business of global environmental governance. Cambridge, Mass: MIT Press, 2005.

LIMIRO, D. Créditos de carbono: Protocolo de Kyoto e projetos de MDL. Curitiba: Juruá, 2009.

LOMBARDI, A. Créditos de carbono e sustentabilidade: os caminhos do novo capitalismo. São Paulo: Lazuli, 2008.

LOPES, D. H. Governança ambiental global, 2008/2009. 180 f. Lisboa, Dissertação (Mestrado em Direito Internacional Ambiental e Relações Internacionais) - Universidade de Lisboa/Faculdade de Direito, 2008/2009.

LORENZONI NETO, A. Contrato de crédito de carbono: análise crítica das mudanças climáticas. Curitiba: Juruá, 2009.

MARTINS, R. D.; FERREIRA. L. C. Uma revisão crítica sobre cidades e mudança climática: vinho velho em garrafa nova ou um novo paradigma de ação para a governança local? Revista de Administração Pública - RAP, v. 45, n. 3, 2011.

MATTOO, A.; SUBRAMANIAN, A. Greenprint: three big changes for countries to take action on climate change. Center for Global Development (CGD). CGD Brief January 2013. Disponível em: <http://www.cgdev.org/publication/greenprintthree-big-changes-countries-cooperate-climate-change $>$. Acesso em: fev. 2013.

MEADOWCROFT, J. Climate change governance: A paper contributing to the 2010 World Bank World Development Report. [S.1.]: The World Bank Development Economics, may 2009. Disponível em: <http://econ.worldbank.org>. Acesso em: mar. 2012.

MELLO, V. de C. Globalização, regionalismo e ordem internacional. Revista Brasileira de Política Internacional, v. 42, n. $1,1999$.

MICHAELOWA, A. Fragmentation of international climate policy - doom or boom for carbon markets? In: LUTKEN, S.; OLSEN, K. H. (Eds.). Progressing towards post-2012 carbon markets. Roskilde: UNEP Riso Centre, 2012.

MILANI, C. R. S. Ecopolítica internacional, movimentos ambientalistas e contestação transnacional na América Latina. Caderno CRH, v. 21, n. 53, maio/ago. 2008.

MOTA, H. G.; TEGA, L. Além dos cobenefícios: como o mercado de carbono pode e deve contribuir para um modelo econômico mais sustentável. Plurale em Revista, n. 33, p. 18-19, jan.-fev. 2013.

OKEREKE, C.; BULKELEY, H. Conceptualizing climate change governance beyond the international regime: a review of four theoretical approaches. Tyndall Centre Working Paper No. 112, Tyndall Centre for Climate Change Research, 2007.

; SCHROEDER, H. Conceptualizing climate change governance beyond the international regime. Global Environmental Politics, n. 9, 2009.

PAIVA, D. S; ALVAREZ, G.; ANDRADE, J. C. S. Cobenefícios de projetos de redução de GEE do mercado voluntário: análise do corredor ecológico Monte Pascoal-Pau Brasil. In: CONGRESSO NACIONAL DE EXCELÊNCIA EM GESTÃO-CNEG, 8., Rio de Janeiro, jun. 2012. Anais.

PASISHNYK, N. As desventuras do mercado de carbono europeu. 2010. Disponível em: <http://exame.abril.com.br/ rede-de-blogs/termometro-global/2010/03/23/as-desventuras-do-mercado-de-carbono-europeu/>. Acesso em: ago. 2011.

PEREIRA, L.C. B. O público estatal na reforma do Estado. Rio de Janeiro: Fundação Getúlio Vargas, 1999.

POHLMANN, A. Local climate change governance. In: ENGELS, A. (Ed.). Global transformations towards a low carbon society. Working Paper Series n. 5, Hamburg: University of Hamburg/Klima Campus, 2011.

PUPPIM DE OLIVEIRA, J. A. Instrumentos econômicos para gestão ambiental: lições das experiências nacional e internacional. Salvador, Bahia: Centro de Recursos Ambientais/ NEAMA, 2003.

RHODES, R. Understanding governance: policy networks, governance, reflexivity and accountability. Buckingham: Open University Press, 1997.

ROSENAU, J. N. Governança, ordem e transformação na política mundial. In: __ _ _CZEMPIEL, E. Governança sem governo: ordem e transformação na política mundial. Brasilia: Ed. UnB e Imprensa Oficial do Estado de São Paulo, 2000.

SANTOS, M. H. C. Governabilidade, governança e democracia: criação da capacidade governativa e relações executivo-legislativo no Brasil pós-constituinte. DADOS - Revista de Ciências Sociais, v. 40, n. 3, 1997.

SEIFFERT, M. E. B. Mercado de carbono e Protocolo de Quioto: oportunidades de negócio na busca da sustentabilidade. São Paulo: Atlas, 2009.

SILVA JÚNIOR, A. C.; ANDRADE, J. C. S. Tecnologias mais limpas e desenvolvimento sustentável no Brasil: contribuição 
de projetos de MDL. RACEF - Revista de Administração, Contabilidade e Economia da FUNDACE, v. 4, 2011.

SIMONI, W. F. Mercado de carbono. In: FUJIHARA, M. C.; LOPES, F. G. Sustentabilidade e mudanças climáticas: guia para o amanhã. São Paulo: Terra das Artes Editora e Editora Senac São Paulo, 2009.

SOUZA, A. L. R.; PAIVA, D. S.; ANDRADE, J. C. S. Perfil do mercado voluntário. In: ENCONTRO NACIONAL DE GESTÃO EMPRESARIAL E MEIO AMBIENTE-ENGEMA, 13., dez. 2011. São Paulo. Anais.

STRECK, C.; LIN, J. Making markets work: a review of CDM performance and the need for reform. The European Journal of International Law, v. 19, n. 2, p. 409-442, 2008.

SUTTER, C.; PARREÑO, J. C. Does the current clean development mechanism (CDM) deliver its sustainable development claim? An analysis of officially registered CDM project. Climatic Change, v. 84, n. 1, p. 75-90, 2007.

UN ENVIRONMENT PROGRAMME (UNEP). Clean Development Mechanism (CDM)/Joint Implementation (JI) pipeline analysis and database. 2012. Disponível em: $<\mathrm{http}$ ://www. cdmpipeline.org>. Acesso em: maio 2012.

UNITED NATIONS FRAMEWORK ON CLIMATE CHANGE COMBAT (UNFCCC). Regional Distribution: Nairobi Framework. 2012. Disponível em: <http://cdm.unfecc.int/ Nairobi_Framework/index.html $>$. Acesso em: maio 2012.
VEIGA, J. E. Não é que os empresários vejam a sustentabilidade como obstáculo - ela é mesmo um obstáculo. In: ARNT, R. (Org.). O que os economistas pensam sobre sustentabilidade. São Paulo: Ed. 34, 2010.

VENTURA, A. C.; ANDRADE, J. C. S. Ação contestatória de movimentos sociais contra projetos de Mecanismos de Desenvolvimento Limpo (MDL): análise de conflitos socioambientais no contexto latino-americano. América Latina: conceptos y conflitos, San José, Costa Rica: Editorial Nuevas Perspectivas, v.1, p. 149-178, 2011.

VIOLA, E. The Great emitters of carbon and the perspectives for an agreement on mitigation of global warming. In: DIAS, P. L. et al. (Orgs.). Public policy, mitigation and adaptation to climate change in South America. São Paulo: Instituto de Estudos Avançados da Universidade de São Paulo, 2009.

WEISS, J. S.; PINHEIRO DO NASCIMENTO, E. Límites de la cooperación internacional ambiental: el caso del Programa Piloto para La Protección de los Bosques Tropicales de Brasil. Iconos - Revista de CienciasSociales, n. 37, 2010.

WORLD BANK. World Bank development report 1992: development and the environment. Nova York: Oxford University Press, 1992.

WORLD METEOROLOGICAL ORGANIZATION-WMO. WMO Statement on the Status of the Global Climate in 2011. WMO no. 1085. Geneva, Suiça, 2012.

Recebido em 20 de novembro de 2012. Aceito em 11 de outubro de 2013. Publicado em dezembro de 2013. 